\title{
Ecoturismo no Parque Nacional Serra da Capivara: trata-se de uma prática sustentável?
}

\section{The Ecotourism in National Park Serra da Capivara: it is one practice sustainable?}

\author{
Raimundo Coelho de Oliveira Filho ${ }^{1}$ \\ Maria do Socorro Lira Monteiro²
}

\begin{abstract}
Resumo
Este artigo analisa o ecoturismo enquanto atividade geradora de melhorias econômica, social e de preservação ambiental nos municípios piauienses de Coronel José Dias e São Raimundo Nonato, onde se localiza o Parque Nacional Serra da Capivara (PNSC). Nesse sentido, analisaram-se as condições da infra-estrutura receptiva dos municípios e do Parque, abordaram-se demanda e oferta turísticas e avaliaram-se as potencialidades e limitações do PNSC para o ecoturismo. A pesquisa demonstrou que 49,89\% dos ecoturistas estariam dispostos a pagar pela manutenção das funções do PNSC e que 95,79\% dos visitantes reconheceram sua importância patrimonial, histórica e cultural. Ademais, constatou-se a necessidade de investimentos na melhoria da infra-estrutura urbana. Logo, infere-se que a atividade proporciona a preservação ambiental, mas ainda não se traduz em progressiva melhoria das condições de vida das comunidades locais.
\end{abstract}

Palavras-chave: ecoturismo; valoração contingente; unidade de conservação.

\begin{abstract}
This essay examines ecotourism as an activity capable of generating economical and social improvement as well as of helping preserving the environment in the municipalities of Coronel José Dias and São Raimundo Nonato, Piauí, where is located the Serra da Capivara National Park (PNSC, in Portuguese). In that sense, I analyzed the situation of the receptive infrastructure found in the two cities and in the park, the tourism supply and demand, and potentialities and limitations for ecotourism in the Serra da Capivara National Park. The research demonstrated that 49.89\% of the ecotourists would pay for the maintenance of the several functions of the park and that $95.79 \%$ of the visitors acknowledge the historical and cultural value of the park as well as its importance as a heritage site. I also perceived that investments for improving the urban infrastructure will be needed. Therefore, I conclude that the activity provides environmental preservation, but has not yet been translated into improvement in the quality of life for local communities.
\end{abstract}

Keywords: ecotourism; contingent valuation; conservation unity.

\footnotetext{
1 Economista. Mestrando em Desenvolvimento e Meio Ambiente (UFPI-TROPEN-PRODEMA). E-mail: rdocoelho@gmail.com

${ }^{2}$ Economista. Professora da Universidade Federal do Piauí, Centro de Ciências Humanas e Letras, Departamento de Ciências Econômicas. E-mail: socorrolira@uol.com.br
} 


\section{Introdução}

Com a finalidade de conciliar os interesses dos indivíduos e dos distintos segmentos da sociedade, criaram-se arranjos institucionais para a proteção do patrimônio natural por meio de diferentes categorias de Unidades de Conservação. De acordo com o Sistema Nacional de Unidades de Conservação da Natureza (SNUC) (2000), os principais argumentos que explicam a importância da conservação da biodiversidade são: contribuição econômica direta, através da imensa quantidade de produtos alimentares, farmacêuticos e de uso industrial derivados da fauna e flora, os quais auxiliam, ou podem vir a auxiliar, a vida humana e manutenção dos ciclos ambientais gerais do planeta: água, climas, nutrientes, etc.

Entre os diversos tipos de Unidades de Conservação, têm-se os Parques Nacionais, constituídos de áreas protegidas que se destinam à preservação de ecossistemas naturais de grande relevância ecológica, cênica, científica, cultural, educativa e recreativa. Dos 62 Parques Nacionais existentes no Brasil, distingue-se o Parque Nacional Serra da Capivara (PNSC), situado na região sudeste do estado do Piauí, que possui significativa importância histórica, cultural e ambiental para o Brasil e até mesmo para o mundo, devido aos registros da presença humana que remonta a mais de 50.000 anos, nos mais de 1.000 sítios arqueológicos catalogados até junho de 2007, além de apresentar fauna e flora específicas do bioma caatinga e da beleza cênica de suas formações rochosas.

O PNSC foi criado em 05 de junho de 1979, com uma área de 100.000 hectares, nos municípios de Brejo do Piauí, Coronel José Dias, João Costa e São Raimundo Nonato, inseridos na região semi-árida, que historicamente necessita da implementação de ações amparadas nos pressupostos do desenvolvimento sustentável. Nesse contexto, o PNSC apresenta-se como atração de fluxos ecoturísticos para os municípios que o abrangem, com a possibilidade de geração de emprego e renda, assim como valorização cultural e natural, haja vista as grandes dificuldades socioeconômicas locais, explicitadas pelo Índice de Desenvolvimento Humano (IDH) de 2000: Brejo do Piauí 0,54, Coronel José Dias 0,58, João Costa 0,59 e São Raimundo Nonato, 0,68 (PNUD).

Esse panorama explicita a relevância de investigar as possibilidades de ganhos econômicos, sociais, culturais e ambientais que o ecoturismo praticado no PNSC pode gerar para as comunidades dos municípios de Coronel José Dias e São Raimundo Nonato. A concentração do estudo nos dois municípios decorre da constatação de que apenas ali há arranjos institucionais de suporte à atividade turística, como lojas de artesanato, guias de turismo, entrada aos mais importantes atrativos naturais e culturais do PNSC, principais condições que 
favorecem o acesso: rodoviária e aeroporto internacional, em fase de construção, além da grande oferta de hotéis e pousadas e serviços de alimentação. Assim, o presente artigo objetiva analisar o ecoturismo enquanto atividade geradora de melhorias econômica e social para as comunidades circunvizinhas e para a preservação ambiental do PNSC.

Para o desenvolvimento do estudo, realizou-se levantamento bibliográfico e estatístico com a finalidade de discernir, descrever e analisar as atividades do turismo e ecoturismo, assim como pesquisa de campo para a obtenção dos dados primários, na qual adotou-se o método de valoração econômica ambiental, que, em conformidade com Ortiz (2003), busca valorar economicamente um recurso ambiental através da determinação do que é equivalente, em termos de outros recursos disponíveis na economia, dos quais os indivíduos estariam dispostos a abrir mão de maneira a obter uma melhoria de qualidade ou quantidade do recurso ambiental.

A análise da valoração econômica ambiental do PNSC embasou-se no Método de Valoração Contingente (MVC) que, de acordo com Kealy e Turner (1993, apud Martins, 2002), utiliza questões abertas e fechadas para a obtenção da Disposição a Pagar (DAP) ou não. Além disso, integram o MVC distintos instrumentos que viabilizam a valoração dos recursos ambientais, como os Cartões de Pagamento, que se configuram como uma técnica que estabelece um conjunto de valores negociados com as pessoas. Utilizou-se nesta pesquisa esta técnica por julgá-la a mais adequada para captar ou não a DAP dos ecoturistas, manter as funções do PNSC e para caracterizar social e economicamente os visitantes, além de fornecer informações essenciais ao estudo da atividade turística.

De acordo com Dencker (1998), a coleta de dados pode desenvolver-se com aplicação de questionários via telefone, correios ou contato direto, porém, a mais usada na área de turismo, devido facilitar a obtenção de informações com maior veracidade, é o contato direto, que foi usado na presente pesquisa, sendo o Centro de Visitantes do PNSC, o local escolhido para a aplicação dos questionários. A aplicação foi executada em julho de 2006 com a colaboração de 06 guias de turismo do PNSC.

Ademais, realizou-se pesquisa junto a 17 personalidades dos municípios de Coronel José Dias e São Raimundo Nonato, algumas escolhidas de forma aleatória e outras por estarem vinculadas a diversos segmentos relativos à atividade ecoturística, como os Secretários de Turismo, os representantes dos setores dos meios de hospedagem, dos serviços de alimentação, de transportes, da produção artesanal . Participaram instituições como o Serviço de Apoio à Micro e Pequena Empresa (SEBRAE), Serviço Nacional de Aprendizagem 
Profissional (SENAC) e Serviço Social do Comércio (SESC). A aplicação do questionário tinha como objetivo captar informações quanto às condições reais e perspectivas de exploração do ecoturismo, assim como perceber o papel dos atores sociais no processo de desenvolvimento da atividade na região do PNSC.

\section{Turismo e Ecoturismo}

A atividade turística é considerada mais antiga que o próprio conceito. Em termos históricos, o turismo iniciou quando o homem deixou de ser sedentário e passou a viajar, motivado principalmente pela necessidade de comércio (Ignarra, 2001).

A definição de atividade turística pioneira e ainda utilizada na academia foi elaborada pelo economista austríaco Herman von Schullard, que, em 1910, a explicitou como o somatório das operações, especialmente as de natureza econômica, diretamente relacionadas com a entrada, permanência e deslocamento de estrangeiros para dentro e para fora de um país, cidade ou região. Ou seja, turismo é resultante da compreensão dos termos deslocar-se, viajar e fazer turismo. Logo, deslocar consiste no ato praticado por pessoas que mudam de cidade, região ou país, que residem em outros locais, sem retorno imediato a localidade de origem, para atender necessidades de emprego, questões familiares e segurança, sem importar-se com as condições dos meios de transporte ou acomodação. Viajar é o ato de ir temporariamente de um lugar para outro com a intenção de retornar enquanto que fazer turismo pressupõe uma viagem temporária que exige infra-estrutura adequada (Oliveira, 2000).

De acordo com Faria (2001), a atividade turística deve ser considerada como um processo completo, que vai desde a divulgação correta da imagem do local a ser visitado pelo turista, atenção com sua permanência e satisfação, até a volta à origem, de modo que a localidade turística permaneça conservada, no longo prazo, para a continuidade do atendimento qualificado, garantia de boas condições de vida para a população local e preservação do meio ambiente.

Segundo Trigo (1993), as distintas definições de turismo devem considerar os contextos histórico, temporal e espacial, já que a atividade envolve cultura, arte, qualidade de vida e lazer.

Por conseguinte, em consonância com Beni (2006), para um território tornar-se destino turístico é indispensável que possua atrativos e infra-estrutura básica. Os primeiros podem ser 
naturais (montanhas, rios, cachoeiras, ilhas, praias, dunas) culturais (monumentos, danças folclóricas, arquitetura, museus, sítios históricos) ou programados (eventos). Dessa forma, cada local define em que tipo(s) de turismo suas características se enquadram. Assim, de acordo com as diversas motivações, necessidades e preferências dos praticantes, o turismo é classificado como ecológico, agroturístico, climático ou hidrotermal, paisagístico, desportivo, étnico-histórico-cultural, temático, cívico institucional, religioso, urbano, de recreação, sociofamiliar, de incentivos e de jogos (ou cassinismo).

A amplitude da atividade turística relaciona vários tipos de turismo, condensados em dois segmentos: de massa e alternativo. O turismo de massa transfere poucas qualidades de compensação para a região receptiva, população ou base de recursos naturais. Enquanto que o turismo alternativo ramifica-se em formas que demonstram coerência com os valores natural, social e comunitário, o que permite a hospedeiros e hóspedes o desfrute de uma interação positiva e conveniente assim como compartilhamento de experiências (Rejowski, 2002).

Essa constatação foi decorrente do crescente debate sobre o desenvolvimento sustentável a partir dos anos de 1980, buscando-se uma alternativa social e ecológica para o turismo de massa, no sentido de garantir que as políticas públicas não se concentrem somente nas necessidades econômicas, mas enfatizem da mesma forma o interesse por um ambiente não degradado e que proporcionem também a satisfação da comunidade receptora (Fennell, 2002).

Segundo Dias (2003), entre os distintos tipos de turismo, destaca-se o ecoturismo, com seus diversos conceitos, todos apresentando elementos comuns, tais como: educação, interpretação ambiental, organização para pequenos grupos, gerência por pequenas empresas especializadas e comumente de propriedade local, proteção de zonas naturais, alternativa de oportunidade de emprego e renda para as comunidades locais e instrumento de conscientização sobre a conservação dos ativos naturais e culturais por parte de habitantes e turistas.

Para Kinker (2002), a análise evolutiva do conceito de ecoturismo pode ser pensada como uma linha contínua, sendo que em uma das extremidades encontra-se pouca responsabilidade com o meio ambiente natural e cultural, em que qualquer tipo de turismo traz necessariamente impacto negativo, enquanto na outra se observa o respeito ao meio ambiente, a natureza e a cultura.

Rodrigues (2003, p. 31) considera o ecoturismo "uma atividade econômica de baixo impacto ambiental, que se orienta para áreas de significativo valor natural e cultural, e que através das atividades recreacionais e educativas contribui para a conservação da biodiversidade e 
da sociodiversidade", resultando, por conseguinte, em ganhos para as comunidades receptoras.

De acordo com Swarbrooke (2000), a definição de ecoturismo varia conforme o comportamento do agente econômico. Para o turista, trata-se de uma atividade que é sinônimo de férias modernas, pois confere elevado status aos praticantes, frequentemente identificada com turismo de qualidade. Para a indústria, consiste num produto que oferece margens de lucros atraentes e dispõe de um mercado extenso e em expansão. E, para as comunidades receptoras, é rentável, embora em menor proporção que o turismo de massa.

Nessa perspectiva, reconhece-se que a atividade ecoturística exige a participação efetiva da comunidade local, responsabilidade social, cultural e ecológica, além da interação com o turista, preocupando-se e comprometendo-se com a preservação do meio ambiente, minimizando os impactos negativos e maximizando os positivos, com vista ao desenvolvimento sustentável. Portanto, define-se como uma atividade que busca a geração de emprego e renda, isto é, criação de oportunidades econômicas para o bem-estar das populações locais, aliada à conservação do meio ambiente.

\section{Caracterização da Área de Estudo}

Para a compreensão da realidade social, econômica e ambiental da área sob investigação, caracterizou-se o PNSC e os municípios de Coronel José Dias e São Raimundo Nonato.

\subsection{Parque Nacional Serra da Capivara}

O PNSC foi criado com uma área de 100.000 hectares, posteriormente ampliado pelo Decreto $\mathrm{n}^{\mathrm{o}}$. 99.193 de 12.03.1990 para 129.140 hectares. Localizou-se inicialmente nos municípios de Canto do Buriti, São João do Piauí e São Raimundo Nonato, mas, com a emancipação política na década de 1990 de vários municípios do estado, a conformação territorial do PNSC centrou-se nos municípios de Brejo do Piauí, Coronel José Dias, João Costa e São Raimundo Nonato.

Segundo a FUMDHAM (2006), no PNSC encontram-se sítios arqueológicos localizados num contexto geológico bastante diversificado, que retrata o processo de formação da região há 240 milhões de anos, com o levantamento do fundo do mar, contendo os mais antigos vestígios dos primeiros povos que viveram na América; ou seja, apresenta a maior 
concentração de arte pré-histórica, reconhecida pela UNESCO em 1991, como Patrimônio Natural da Humanidade.

Os fatores que fundamentaram a criação do PNSC, expressam-se de natureza diversa, como:

Cultural - derivada da concentração dos cerca de 900 sítios arqueológicos com mais de 40.000 pinturas e gravuras rupestres, que demonstram vestígios da presença humana na região há mais de 50.000 anos, além da presença de artefatos como ossos, cerâmicas e restos de fogueiras;

Ambiental - em função de a região ser fronteiriça entre as formações geológicas da bacia sedimentar Maranhão-Piaú e a depressão periférica do rio São Francisco, com paisagens variadas nas serras, vales e planície, e configurar-se como único Parque Nacional brasileiro cuja área total encontra-se no domínio morfoclimático das caatingas, com vegetação típica desse domínio;

Turística - por possuir paisagens naturais surpreendentes, manifestando potencial para o turismo cultural e ecológico, enquanto uma alternativa de desenvolvimento.

Conforme o Ministério do Turismo (2006), a capacidade de recepção do PNSC é de 02 (dois) milhões de turistas por ano, pois possui uma infra-estrutura de acesso com 16 circuitos ou 128 sítios arqueológicos abertos a visitações, com três guaritas de entrada com guardas permanentes, rádio, toaletes, loja de souvenir, um Centro de Visitantes com auditório, exposição e lanchonete, $300 \mathrm{~km}$ de trilhas carroçáveis, mais de $100 \mathrm{~km}$ de trilhas para

pedestres, placas indicativas e setas ao longo dos circuitos turísticos e 35 condutores de turistas.

A temperatura média anual é de $28^{\circ} \mathrm{C}$, sendo a máxima de $35^{\circ} \mathrm{C}$ e a mínima, de $12^{\circ} \mathrm{C}$. Apresenta falta de água, relacionada com as altas taxas de evaporação, cujos índices encontram-se entre $2.400 \mathrm{~mm}$ e $2.800 \mathrm{~mm}$, acentuando-se no mês de setembro, com a evaporação diária média variando de 3,5mm em março a 12,4mm em agosto (Arruda, 1997).

\subsection{Município de São Raimundo Nonato}

São Raimundo Nonato foi criado pela Lei $n^{\circ}$. 669 de 25/06/1912, desmembrado dos municípios de Jaicós e Jerumenha, localizado no sudeste do Piauí. Limita-se ao norte com os municípios de Brejo do Piauí e João Costa, ao sul com Fartura do Piauí e Dirceu Arcoverde, a leste com Coronel José Dias e São Lourenço do Piauí e a oeste com São Braz do Piauí, 
Bonfim do Piauí e Várzea Branca. Compreende uma área de $2.428 \mathrm{~km}^{2}$, com uma população de 26.880 habitantes e densidade demográfica de 11,94 hab $/ \mathrm{km}^{2}$ (IBGE, 2000).

Entre 1991 e 2000, a taxa média de crescimento anual da população total foi de $1,50 \%$, passando de 23.637 para 26.890 , enquanto que a taxa da população urbana foi de $12,18 \%$, aumentando de 57,03\% para 63,97\%, com 9.352 domicílios (PNUD, 2003).

O comércio é a atividade econômica preponderante, haja vista existirem 329 estabelecimentos com CNPJ e alvará de funcionamento. Dentre estes, predominam os varejistas de gêneros de primeira necessidade, como alimentos, vestuário, remédios, decorrentes do fato de São Raimundo Nonato ser o centro urbano de maior influência em toda a microrregião, tornandose assim seu principal centro comercial. Destaque-se que, do total de estabelecimentos comerciais, três lojas de artesanato retratam as pinturas rupestres do PNSC (PNUD, 2002a).

A estrutura produtiva do município caracteriza-se pela agricultura de sequeiro, em muitos casos de subsistência, criação de animais de pequeno e médio porte e pelo turismo, que a partir da década de 1990 ganha impulso, com a abertura a visitações ao PNSC. Quanto às instituições financeiras, o município conta com três agências bancárias (Banco do Brasil, Caixa Econômica Federal e Banco do Nordeste), uma casa lotérica e, na agência dos Correios, funciona um banco postal.

O PNSC incrementou a prestação de serviços turísticos, principalmente hotéis e pousadas de pequeno porte. O sistema de hospedagem ampliou-se com a abertura do PNSC para visitação pública, embora sem planejamento, na medida em que apenas em 2006 realizaram-se pesquisas de demanda e oferta turística, pela Fundação Centro de Pesquisas Econômicas e Sociais do Piauí (CEPRO). Ressalta-se que a implantação da rede hoteleira não pode ser creditada tão somente ao turismo, uma vez que São Raimundo Nonato configura-se como um lócus de pequenos comerciantes, representantes de vendas, caminhoneiros, que buscam meios de hospedagem mais simples e de menor custo, sem preocupação com a qualidade do serviço. O município conta também com um grupo de 29 condutores de turistas, formados pela Fundação Museu do Homem Americano e IBAMA e organizados em torno de uma associação (PNUD, 2002a).

Em 2005 o terminal rodoviário foi desativado para ser transformado em um centro comercial (centro multiuso) com a finalidade de agrupar diversos estabelecimentos voltados para a prestação de serviços relacionados com o turismo, e uma nova rodoviária está em fase de 
conclusão. São Raimundo Nonato possui também serviços de táxi, mototáxi e uma agência de turismo.

\subsection{Município de Coronel José Dias}

A emancipação política de Coronel José Dias efetivou-se pela Lei Estadual n ${ }^{\circ} .4 .477$ de 29 de abril de 1992, mas foi instalado somente em 01 de janeiro de 1993, quando o território que compreendia o povoado Várzea Grande foi desmembrado do município de São Raimundo Nonato. Possui uma superfície de $1.822 \mathrm{~km}^{2}$, representando $0,72 \%$ do estado do Piauí, $0,12 \%$ da região Nordeste e $0,02 \%$ do território brasileiro. O principal acesso é a BR-020, distanciado $33 \mathrm{~km}$ de São Raimundo Nonato e $458 \mathrm{~km}$ de Teresina, a capital do Estado (IBGE, 2006).

O município possui uma população de 4.415 pessoas, representando $0,16 \%$ da população do estado, com uma densidade demográfica de 2,42 hab/ $\mathrm{km}^{2}$, sendo predominantemente rural, pois consta com $77 \%$ das pessoas vivendo zona rural do município, onde a média de habitantes por domicílio chega a 5,6, enquanto que na zona urbana a média é de 2,6 (IBGE, 2000).

Localiza-se no sopé da Serra da Capivara, na região sudeste do estado, na microrregião de São Raimundo Nonato e limita-se ao norte com João Costa, ao sul com Dirceu Arcoverde e Remanso na Bahia, a leste com Dom Inocêncio e a oeste com São Raimundo Nonato e São Lourenço do Piauí.

Do ponto de vista econômico, o município apresenta quatro espaços geográficos diferenciados: a sede, onde se situam os principais pontos comerciais; o Sítio do Mocó, no qual se encontra a entrada do PNSC e onde são desenvolvidas as principais atividades turísticas; Lajes de Pedra, onde prevalece a atividade de caprino-ovinocultura; e os povoados localizados ao longo do rio Piauí, nos quais, além da caprino-ovinocultura, desenvolvem-se também a apicultura e a cajucultura.

A atividade turística no município resulta basicamente da atratividade do PNSC, desenvolvida, principalmente, no povoado Sítio do Mocó, que conta com um camping, um restaurante e uma loja de produtos artesanais, na localidade Barreirinho, na qual se realiza a atividade de cerâmica com a marca Serra da Capivara, destinada aos mercados interno e externo, comercializada com vários países da Europa. Na Sede do município existem 21 empreendimentos de comércio informal (destes, 03 são pousadas e 05 são lanchonetes), 10 
microempresas que prestam serviços diversos, 02 cerâmicas e 01 empresa de beneficiamento de mel.

\section{Análise da Pesquisa de Campo}

Analisam-se nesse item os dados obtidos na pesquisa de campo realizada junto a representantes de segmentos socioeconômicos dos municípios de São Raimundo Nonato e Coronel José Dias e aos turistas do Parque Nacional Serra da Capivara, com o objetivo de avaliar a atividade ecoturística, a valoração econômica ambiental do PNSC e os entraves para que o ecoturismo proporcione uma melhoria econômica e social das comunidades locais. Para tanto, utilizou-se o Método de Valoração de Contingente (MVC), que consiste, inicialmente, em desenhar o perfil socioeconômico do usuário do PNSC, avaliar a infra-estrutura receptiva e questionar o entrevistado quanto a sua Disposição a Pagar (DAP) pela conservação/preservação do Parque.

\subsection{Percepções da comunidade do entorno do PNSC sobre o ecoturismo}

Com o propósito de analisar a relação existente entre o ecoturismo praticado no PNSC e a comunidade local, procurou-se, particularmente, compreender como tal comunidade percebe a Unidade de Conservação e o desenvolvimento da atividade na região, assim como os impactos dessa atividade no cotidiano da população e a importância dos principais fatores que possibilitam o crescimento da atividade ecoturística na região.

Conforme já foi enfatizado acima, a pesquisa de campo realizada nos municípios de Coronel José Dias e São Raimundo Nonato, com uma abrangência que corresponde a 17 representantes dos segmentos econômicos, sociais e públicos relativos à atividade ecoturística, escolhidos de forma aleatória, em função da importância junto ao seu ramo, visou captar informações quanto às condições reais de exploração e perspectivas do ecoturismo, assim como o papel dos atores sociais no processo de desenvolvimento da atividade na região do PNSC.

Dos 17 representantes, $62 \%$ são do sexo masculino e $38 \%$ do feminino, evidenciando-se a supremacia masculina na representatividade das instituições e empresas da comunidade local. Além disso, verificou-se que $24 \%$ dos entrevistados possuem ensino fundamental, $47 \%$ médio e $29 \%$ superior. 
Identificou-se por meio da investigação que $81 \%$ do universo consideraram o PNSC como local de preservação da natureza e fonte geradora de emprego e renda. Desses, 94\% estimaram que o Parque propicia melhoria no nível de vida das comunidades de São Raimundo Nonato e Coronel José Dias, pois gera emprego e renda, como foi exemplificado pelos funcionários do parque, da FUMDHAM, da Cerâmica Serra da Capivara e dos guias de turismo. Os investimentos em infra-estrutura no PNSC também requerem a utilização da mãode-obra local na construção de passarelas, abertura e limpeza das trilhas e preservação dos sítios arqueológicos. Para 6\% dos entrevistados, a criação da Unidade de Conservação possibilitou a exploração de atrativos turísticos alternativos.

O conjunto dos representantes reconhece a importância da atividade ecoturística, em função de sua capacidade de atrair recursos financeiros e de fortalecer a cultura local. Neste sentido, comprovaram-se as facetas positivas do ecoturismo, principalmente como mecanismo estimulador da economia e da difusão da cultura, na medida em que $81 \%$ e $19 \%$ consideraram o ecoturismo como influência positiva e negativa, respectivamente, para o desenvolvimento de suas atividades. O impacto positivo da atividade relaciona-se com o aumento dos ganhos econômicos, decorrente do crescimento do fluxo turístico, assim como com a preservação e conservação do PNSC, ao possibilitar espaço para recreação e despertar o interesse da juventude pela problemática ambiental. O impacto negativo da atividade refere-se ao insuficiente fluxo de visitantes.

Para os integrantes da pesquisa, a dinamização do ecoturismo na região do PNSC exige a melhoria da infra-estrutura, como saneamento básico, limpeza urbana, comunicação, sinalização, rodovias, hotéis e restaurantes; organização da oferta turística; introdução de outros atrativos nos roteiros turísticos (Pedra do São Vitor, Balneário Jenipapo, festas populares, Parque Nacional Serra das Confusões e açude Petrônio Portela); qualificação de mão-de-obra através de cursos técnicos e profissionalizantes; instalação de centros de apoio ao turista; integração do Poder Público, setor privado e população; e organização de eventos e oficinas culturais.

Essa configuração demonstra o reconhecimento do ecoturismo como uma atividade que possibilita alternativas de geração de emprego e renda, melhora a qualidade de vida das pessoas e induz à preservação ambiental na região do PNSC. Destarte, faz-se mister que os agentes socioeconômicos, coordenados pelo Poder Público, elaborem uma política municipal de ecoturismo, que estimule empresários locais a estabelecerem e ampliarem empreendimentos e incentive a formação de associações e/ou cooperativas que possam ofertar 
serviços de qualidade aos ecoturistas. No entanto, salienta-se que os investimentos devem estar associados à mitigação dos custos sociais e ambientais, para serem evitados os impactos negativos da atividade.

\subsection{Perfil do visitante do PNSC}

Embasado nas informações do escritório regional do IBAMA em São Raimundo Nonato sobre a visitação do PNSC, mês a mês, durante o ano de 2005, estabeleceu-se o mês de julho como o mais apropriado para a aplicação da pesquisa de campo, devido à concentração de visitação. Assim, constatou-se que ,em julho de 2006, 1.175 pessoas visitaram o PNSC. Ademais, como esta pesquisa objetivou analisar os ecoturistas e não os excursionistas, ou seja, pessoas cuja visita não ultrapassa 24 horas, o universo identificado foi de 451 visitantes, isto é, a totalidade dos ecoturistas do mês de julho de 2006.

Através da pesquisa, detectou-se que $94,68 \%$ dos visitantes do PNSC são brasileiros e somente 5,32\% são estrangeiros, configurando uma limitação do fluxo internacional. Tais dados explicitaram que, apesar da divulgação em nível internacional da riqueza arqueológica do Parque, a atratividade ainda é pequena decorrente da carência de infra-estrutura receptiva para a dinamização da atividade turística, como a inconclusão da construção do aeroporto internacional de São Raimundo Nonato e a distância do Parque em relação a Teresina (PI) e Petrolina (PE), cidades mais próximas que possuem vôos diários para grandes centros nacionais.

Do total de ecoturistas de origem brasileira, 50,82\% são piauienses, enquanto $14,52 \%$ são procedentes de Pernambuco, 9,84\% de São Paulo e 7,73\% da Bahia, o que demonstra que o fluxo turístico interno é predominantemente regional, sendo que 79,39\% dos visitantes são oriundos do Nordeste, $12,65 \%$ do Sudeste, 3,75\% do Centro-Oeste, 3,74\% do Sul e 0,46\% do Norte. Ademais, destaca-se a presença de pessoas provenientes de cidades próximas ao PNSC, como Petrolina (PE), Juazeiro, Remanso e Casa Nova (BA). Quando somado aos excursionistas (pessoas que vistam o PNSC em um dia e retornam à cidade de origem), notouse que o ecoturismo do PNSC é realizado basicamente por indivíduos que residem num raio de 500 km de distância.

Quanto ao grau de instrução, verificou-se que 46,34\% dos visitantes possuem ensino superior completo, 30,16\% nível superior incompleto, 11,09\% segundo grau completo, 8,87\% segundo grau incompleto e $1,11 \%$ ensino fundamental completo. A prevalência da visitação por pessoas com nível educacional elevado, facilita a aplicação dos princípios norteadores do 
ecoturismo, já que se trata de turistas que buscam a interpretação ambiental e conhecimento histórico/cultural local, possibilitando o fortalecimento da prática do ecoturismo.

Em relação à ocupação principal dos ecoturistas, 34,15\% são professores, $27,81 \%$ estudantes, 3,99\% funcionários públicos, 3,55\% comerciantes, 3,33\% empresários, 2,88\% médicos, 1,55\% secretários, $1,55 \%$ administradores, $1,11 \%$ bancários e $1,11 \%$ engenheiros civis. Outros profissionais representam inexpressivo percentual e 3,55\% não mencionaram a atividade desenvolvida. Esse panorama expressou que entre os ecoturistas do PNSC predominou o perfil com relativo conhecimento científico, pois o objetivo desses visitantes centrava-se no lazer, estudos e pesquisas, particularmente nas áreas de arqueologia, paleontologia, geologia, zoologia, biologia, ecologia ou manifestação cultural (do presente ou do passado). Corroborou para esse perfil, o fato de 59,21\% dos ecoturistas serem professores e estudantes, com interesse no arcabouço histórico que a Unidade de Conservação representa e no estudo da flora e fauna da caatinga, através de visitas promovidas por escolas ou universidades. Nesse sentido, denotou-se que a visitação no PNSC integrava, além do ecoturismo, o turismo cultural, educacional, científico e de aventura.

Evidenciou-se que 35,48\% dos visitantes não indicaram rendimento, porém 10,86\% recebem até $\mathrm{R} \$ 350,00,29,93 \%$ auferem renda bruta mensal individual de $\mathrm{R} \$ 350,00$ a $\mathrm{R} \$ 1.050,00$ e $10,20 \%$ recebem de $\mathrm{R} \$ 1.750,00$ a $\mathrm{R} \$ 3.500,00$. Observou-se também que 7,76\% dos turistas possuem renda maior que 10 salários mínimos e 5,76\% estão entre os que ganham de 03 a 05 salários mínimos. Dessa forma, reconheceu-se que parte dos ecoturistas contam com rendimento acima do salário mínimo vigente no Brasil ( $\mathrm{R} \$ 350,00$ em março de 2007). Tais visitantes, portanto, apresentam condições de realizar o turismo alternativo, já que geralmente esse constitui interesse de grupos de pessoas que possuem elevado nível de educação e de renda.

A pesquisa permitiu identificar que os hotéis e pousadas constituem o principal meio de hospedagem dos ecoturistas com 66,74\%, seguido de escolas com 10,20\%, casa de parentes / amigos com 6,43\%, albergue com 6,20\%, Centro Diocesano com 4,41\%, casa alugada com $3,76 \%$, camping com $0,89 \%$ e outros com 1,33\%. Dentre os meios de hospedagens convencionais, somente o albergue e o camping localizam-se no município de Coronel José Dias, os demais se concentram em São Raimundo Nonato.

Quanto à duração da viagem, 47,22\%, 37,92\% e 8,65\% dos visitantes permanecem na região do PNSC 03 (três), 02 (dois) e 04 (quatro) dias, respectivamente, manifestando um ecoturismo de final de semana. Ressalta-se que para 5,99\% dos visitantes a permanência é de 
10 dias e para $0,22 \%$ é de até 180 dias, em função da realização de pesquisas arqueológicas e culturais. Tal panorama expôs a importância do PNSC e do Museu do Homem Americano como atratividade para pesquisadores e estudantes assim como a necessidade dos municípios de São Raimundo Nonato e Coronel José Dias criarem outras ofertas turísticas de caráter artístico, cultural e social, com equipamentos de recreação e lazer, capazes de atrair e manter os turistas por um período de tempo prolongado.

Logo, o perfil do visitante do PNSC apontou para a necessidade premente de divulgação da importância patrimonial, histórica e ambiental do Parque em outras regiões do Brasil e do mundo, no sentido de impulsionar o ecoturismo. Além disso, verificou-se a carência de investimento público em infra-estrutura urbana, o que redundou na conformação de uma atividade turística regional e de curto período de duração.

\subsection{Avaliação da oferta turística}

$\mathrm{Na}$ perspectiva de identificar a oferta turística do PNSC e dos municípios do entorno, pesquisou-se a qualificação dos diversos equipamentos, relacionando as alternativas ótimo, bom, regular, ruim, péssimo e não sabe. Sendo assim, explicitou-se que 77,83\% e 15,96\% dos ecoturistas qualificaram o PNSC como ótimo e bom, expressando assim o reconhecimento de seu patrimônio natural e cultural, o que reforçou a importância de sua preservação. Salienta-se que $70,95 \%$ dos visitantes avaliaram a participação dos guias de turismo como componente fundamental da oferta turística para o pleno conhecimento e entendimento do conjunto dos atrativos do PNSC. Destaca-se, outrossim, que 42,13\% e 43,68\% dos entrevistados julgaram como ótimo e bom a atividade artesanal, respectivamente, expondo a riqueza do material produzido no entorno do PNSC, como a produção de cerâmica na comunidade Barreirinho em Coronel José Dias, que é desenvolvida com artesãos treinados nas escolas da FUMDHAM, geralmente filhos de antigos moradores da área onde foi instalado o Parque.

A pesquisa demonstrou que $41,69 \%$ dos ecoturistas consideraram a hospitalidade local como ótima, verificando-se a aceitabilidade da comunidade local aos visitantes, que, apesar desse cenário, ainda ressente-se de ações que visem capacitar tecnicamente os hospedeiros. Ademais, 33,04\% dos entrevistados reputaram os bares/restaurantes como bom, 26,16\% como regular e 24,17\% não sabem. Quanto às diversões noturnas, 54,77\% dos ecoturistas depreenderam não saber opinar, devido ao fato do visitante não manter contato com os itens analisados ou pela ausência de espaços culturais típicos da região. 
A investigação evidenciou que $42,78 \%$ dos ecoturistas avaliaram a infra-estrutura das cidades como regular/ruim/péssimo. Tal condição relacionou-se à implantação de saneamento básico em São Raimundo Nonato e de abastecimento d'água em Coronel José Dias, ocasionando alteração na pavimentação das ruas. A limpeza urbana consiste em outro fator negativo, em decorrência da exposição de lixo em locais inadequados e da destinação final desse centrar-se em lixão a céu aberto. Constatou-se também a insatisfação dos visitantes quanto aos meios de acesso, pois 39,69\% dos ecoturistas qualificaram como regular/ruim/péssimo, identificando-se inclusive que a pior situação de conservação dos acessos é a do estado da Bahia, utilizados principalmente pelos visitantes que usam o aeroporto de Petrolina-PE ou oriundos dos demais estados do Nordeste. Em relação às diversões noturnas 22,39\% dos ecoturistas julgaram esse item como regular/ruim/péssimo.

Reconheceu-se, então, que a deficiência da prestação de serviços de infra-estrutura, meios de acesso, bares / restaurantes e diversão noturnas de São Raimundo Nonato e Coronel José Dias provocaram efeitos negativos sobre o fluxo turístico, haja vista a curta permanência do ecoturista, concentrada nos finais de semana.

A relevância da capacidade receptiva do PNSC decorreu da infra-estrutura dos sítios arqueológicos manifestada pela placas indicativas, acesso a trilhas, trilhas e centro de visitantes, que apresentaram em média 90\% de ótimo e bom. Os dados demonstraram o potencial de atratividade ecoturística das paisagens naturais e dos 128 sítios arqueológicos do PNSC abertos a visitações.

Do universo de ecoturistas pesquisados, 60,53\% dos entrevistados visitaram outro atrativo além do PNSC. Destes, 76,56\% foram ao Museu do Homem Americano, 6,23\% ao centro de São Raimundo Nonato, 6,23\% as lojas de artesanato e 2,20\% aos bares da cidade. Tal circunstância explicitou a insuficiência de divulgação de atividades culturais e da inexistência de rede entre os diversos equipamentos que compõem a atividade ecoturística na região. Nesse sentido, ressalta-se a importância da organização em rede com ampla divulgação e sistematização, como a criação de um calendário anual de eventos culturais, publicidade sobre os saberes locais e sobre comidas típicas e outras eventuais peculiaridades. Sendo assim, inferiu-se que o PNSC e o Museu do Homem Americano constituem os únicos atrativos com condições adequadas à demanda turística. Não obstante esse cenário, uma expressiva parcela $(86,47 \%)$ dos visitantes expressaram a intenção de retornar à região do PNSC, reforçando o elevado nível de satisfação com a permanência no local. 
Entre as principais atividades praticadas pelos visitantes do PNSC, distinguem-se: caminhadas / acampamentos / contemplação da paisagem (31,11\%), observação da vida selvagem / interpretação da natureza / orientação geográfica (30,22\%), estudos / pesquisas $(23,33 \%)$, convivência e sociabilidade com a comunidade local $(8,77 \%)$, passeios montados / cicloturismo (3,09\%), treking / montanhismo / expedições (1,23\%), escalada / mountain bike / rapel / vôo livre / rally / enduro (0,99\%). Esse panorama expôs que a atração turística do PNSC relaciona-se aos mais diversos perfis de turismo, como científico, ecológico, de aventura ou voltado a terceira idade e estudantes universitários, corroborando a predominância da prática do ecoturismo, ao aliar-se o deslocamento para áreas naturais conservadas e protegidas, buscando-se admirar fauna e flora, com o objetivo específico de estudar as manifestações culturais, internalizando os aspectos de educação e interpretação ambiental, na perspectiva de reduzir a possibilidade de impactos negativos sobre o entorno natural e sociocultural e de contribuir para a geração de benefícios econômicos para as comunidades locais.

Faz-se mister destacar, outrossim, que 95,79\% dos visitantes reconheceram que a existência, manutenção e conservação do PNSC possibilitaram uma melhoria no nível de vida da comunidade, sendo que $3,55 \%$ não consideraram esse fato e $0,67 \%$ não opinaram. Esse contexto despertou a consciência ambiental dos ecoturistas do PNSC, principalmente quanto à responsabilidade com o meio ambiente e com a cultura dos locais visitados, no sentido de que a importância do PNSC consiste não somente na conservação da natureza, mas também no gigantesco acervo arqueológico encontrado em mais de 900 sítios catalogados.

\subsection{Valoração econômica do PNSC}

Para valorar patrimônios ambientais, utilizam-se os métodos de valoração dos recursos ambientais, que consistem em determinar quão melhor ou pior estará o bem-estar das pessoas devido alterações na quantidade, por apropriação, uso ou não uso de ativo ambiental. Dessa forma, estabelece-se o valor de um recurso ambiental pela função de seus atributos, relacionados aos diferentes usos para fins comerciais ou recreativos. Sendo assim, o valor de uso direto baseia-se na utilização dos recursos ambientais, via extração, visitação ou outra atividade de produção ou consumo direto; valores de uso indireto são instituídos pelos benefícios indiretos gerados pelas funções ecossistêmicas; valor de opção é representado pelo montante, em termos monetários, que um indivíduo se dispõe a pagar para conservar um recurso ambiental não utilizado no presente, mas que pode vir a ser explorado no futuro; e valor de não uso ou de existência corresponde ao valor que está dissociado do uso e deriva-se 
de uma posição moral, cultural, ética ou altruística em relação aos direitos de existência de seres não-humanos ou preservação de outras riquezas naturais, mesmo que estas não representem uso atual ou futuro para o indivíduo.

Nessa perspectiva, a identificação das preferências dos visitantes do PNSC quanto à preservação e manutenção do PNSC foi obtida através do MVC, que consiste em um dos métodos de valoração dos recursos ambientais. Destarte, buscou-se averiguar a DAP dos ecoturistas para conservá-lo como área natural e cultural. Para tanto, criou-se um cenário hipotético com o objetivo de determinar o valor atribuído pelos usuários do PNSC, que foi operacionalizado por meio da pergunta: você estaria disposto a pagar mensalmente R $\$ \mathrm{X}$ para manter a conservação/preservação do Parque? Quando obtida a resposta positiva, Cartões de Pagamento com diferentes valores foram apresentados, sendo que os visitantes eram solicitados a escolher o que melhor representa a DAP. Preliminarmente, realizou-se uma pesquisa piloto, que definiu os valores monetários para a pesquisa definitiva: $\mathrm{R} \$ 6,00, \mathrm{R} \$$ 12,00, R\$ 18,00 e R \$20,00. Os resultados da pesquisa estão expostos na Tabela 01.

Tabela 01- Distribuição da DAP e não DAP dos visitantes do PNSC em 2006

\begin{tabular}{|l|c|c|}
\hline \multicolumn{1}{|c|}{ Descrição } & Número & \% \\
\hline $\mathrm{R} \$ 6,00$ & 91 & 20,18 \\
\hline $\mathrm{R} \$ 12,00$ & 56 & 12,42 \\
\hline $\mathrm{R} \$ 18,00$ & 25 & 5,54 \\
\hline $\mathrm{R} \$ 20,00$ & 53 & 11,75 \\
\hline Não está Disposto a Pagar & 226 & 50,11 \\
\hline Total & $\mathbf{4 5 1}$ & $\mathbf{1 0 0 , 0 0}$ \\
\hline
\end{tabular}

Fonte: Pesquisa de campo realizada em julho de 2006.

A Tabela 01 mostrou que dos 451 ecoturistas, 225 estão dispostos a pagar um dos valores apresentados nos Cartões de Pagamento, destes 20,18\%, 12,42\%, 11,75\% e 5,54\% apresentaram DAP de $\mathrm{R} \$ 6,00, \mathrm{R} \$ 12,00, \mathrm{R} \$ 20,00$ e $\mathrm{R} \$ 18,00$, respectivamente. Verificou-se também que 50,11\% das pessoas não estão DAP, por diversos motivos, conforme exposto na Tabela 02. Este cenário demonstrou diferentes aspectos, como a escolha do menor valor por 
20,18\% daqueles que estariam DAP, o qual se relaciona à renda dos ecoturistas ou à concepção de que a proteção da natureza é dever do Estado. Além disso, percebeu-se certo equilíbrio na aceitação dos Cartões de Pagamento, conseqüência dos diferentes níveis de renda, de um lado os que preferiram um valor menor $(\mathrm{R} \$ 6,00)$ com nível de renda baixo ou não consideram a importância da preservação ambiental e, do outro lado, pessoas com nível de renda mais elevado DAP com o maior valor $(\mathrm{R} \$ 20,00)$.

Tabela 02- Motivos do ecoturista pela não DAP para a conservação do PNSC em 2006

\begin{tabular}{|l|r|r|}
\hline \multicolumn{1}{|c|}{ Motivos } & \multicolumn{1}{c|}{ Número } & \multicolumn{2}{|c|}{$\%$} \\
\hline A preservação do PNSC é obrigação do governo & 153 & 67,70 \\
\hline Não tem condições financeiras & 58 & 25,67 \\
\hline Não confia nas instituições que preservam a natureza & 9 & 3,98 \\
\hline Não tem interesse pela preservação ambiental & 6 & 2,65 \\
\hline Total & $\mathbf{2 2 6}$ & $\mathbf{1 0 0}$ \\
\hline
\end{tabular}

Fonte: Pesquisa de campo realizada em julho de 2006.

A Tabela 02 revelou que 50,11\% dos visitantes não estão dispostos a pagar pela manutenção do PNSC, sendo que o principal motivo $(67,70 \%)$ centrou-se na idéia de que a preservação da Unidade de Conservação é obrigação do governo. 25,67\% dos ecoturistas manifestaram que não têm condições financeiras para arcar com o ônus da manutenção do Parque; 3,98\% não confiavam nas instituições responsáveis pela preservação da natureza e 2,65\% não se interessavam pela preservação ambiental. Apesar de constituir-se em conclusão subjetiva, identificaram-se como atitudes de protesto posturas reveladoras de que "a preservação do PNSC é obrigação do governo" ou "não confia nas instituições que preservam a natureza". Ademais, salientou-se que mesmo se posicionando pela não DAP, destes, 95,75\% consideraram importante a preservação e conservação do meio ambiente, porém a responsabilidade do ônus não é individual.

Este contexto corrobora para a necessidade de internalização por parte de diferentes instituições e ONGs dos princípios e mandamentos ecoturísticos com o intuito de gerar informações sobre a importância da preservação e conservação ambiental, de respeitar a 
fragilidade da terra, de deixar somente pegadas nas visitas aos sítios, de levar só imagens, de não jogar lixo, de não levar artefatos das áreas naturais; de se inteirar sobre a geografia, costumes, estilos e culturas da localidade visitada, de dialogar com a comunidade para a continuidade da conservação; de respeitar a privacidade e a dignidade dos outros, de não comprar produtos de espécies da flora e da fauna ameaçada, de seguir sempre os caminhos assinalados, de preservar plantas, de não perturbar animais em seus habitats naturais,assim como de apoiar programas conservacionistas e organizações que trabalham para melhorar o meio ambiente, de incentivar as organizações a subscreverem as diretrizes ambientais e de adotarem códigos ambientais para protegerem lugares e ecossistemas especiais. A significativa incorporação dessas condutas possibilitará o incremento da atividade ecoturística em uma Unidade de Conservação, para proporcionar a satisfação das necessidades da atual e das futuras gerações.

\section{Conclusão}

A presente pesquisa objetivou analisar o ecoturismo enquanto atividade geradora de melhorias econômicas e sociais para as comunidades do entorno do PNSC e a DAP dos ecoturistas para preservação do Parque. Nessa perspectiva, através da análise bibliográfica, constatou-se que o ecoturismo consiste em um significativo instrumento para a melhoria de vida de comunidades locais em decorrência das mudanças econômicas, sociais e introdução de novas tecnologias. No entanto, ressaltou-se que essa atividade econômica pode ser compreendida e praticada tanto como destruidora de recursos naturais, como viabilizadora da preservação do meio ambiente.

Identificou-se a atratividade do PNSC através da análise da demanda turística, particularmente pela diversidade do perfil dos visitantes em diversos tipos de turismo, como: científico, ecológico, de aventura, voltado para a terceira idade e educacional, contudo fícou clara a predominância da prática do turismo alternativo, mais precisamente, o ecoturismo.

Porém, no PNSC preponderou o ecoturismo regional, caracterizado por excursionistas, ou seja, por pessoas que visitam o PNSC em um único dia e retornam a cidade de origem e/ou por visitantes que residem num raio de $500 \mathrm{~km}$ de distância. No entanto, o Parque possui infra-estrutura receptiva avaliada positivamente por mais de $90 \%$ dos visitantes, expressada por meio dos sítios arqueológicos, das placas indicativas, das trilhas, do centro de visitantes e do acesso às trilhas. 
Através da utilização do Método de Valoração Contingente, estimou-se o valor de existência do PNSC como importante atrativo turístico, haja vista o reconhecimento dos ecoturistas do Parque enquanto patrimônio histórico, natural e cultural. Logo, presenciou-se a potencialidade do PNSC como atrativo turístico, não obstante o pequeno fluxo anual de visitantes ser menor que 10 mil pessoas ao ano e o fato de que a metade desses visitantes serem da própria região.

Os representantes dos segmentos socioeconômicos reconheceram o valor do PNSC como mecanismo indutor da melhoria econômica e preservação ambiental, todavia esse contexto ainda se apresenta preferencialmente como potencial. Além disso, admitiram que, para a efetividade dessas condições favoráveis, faz-se necessário estimular os empresários locais a estabelecerem e ampliarem empreendimentos turísticos e contribuírem para formação de associações e/ou cooperativas que possam ofertar serviços de qualidade ao ecoturista.

A problemática da investigação assentada em que o ecoturismo realizado no PNSC configurase uma prática sustentável para os municípios do entorno, justificou-se pelo fato de que a criação de uma Unidade de Conservação na região aberta para visitações contribuiu para o despertar da importância de preservar os recursos naturais com vistas na satisfação das necessidades das gerações presentes e futuras. No entanto, a deficiência na infra-estrutura turística em Coronel José Dias e São Raimundo Nonato constitui um entrave à efetividade sistemática da atividade de forma sustentável.

A exuberância histórica, cultural e natural do PNSC, portanto, expressa o potencial para o desenvolvimento regional. O grande desafio para que isso corra, contudo, consiste na ampliação do fluxo ecoturístico com a finalidade de inserir a região no roteiro turístico internacional. Necessita-se, portanto, do envolvimento de todos os segmentos da sociedade, para que a atividade ecoturística abranja as dimensões econômica, ambiental, social e cultural, no sentido tornar-se instrumento de melhoria da qualidade de vida das comunidades, fonte geradora de renda e mecanismo de conservação e/ou proteção das belezas naturais e riquezas históricas/culturais.

\section{Referências}

ARRUDA, Moacir Bueno. 1997. Conservação, ecologia humana e sustentabilidade na caatinga: estudo da região do Parque Nacional da Serra da Capivara (PI). Brasília: Instituto Brasileiro do Meio Ambiente e dos Recursos Naturais Renováveis.

BENI, Mario Carlos. 2006. Análise estrutural do turismo. 11. ed. São Paulo: SENAC. 
DENCKER, Ada de Freitas Maneti. 1998. Métodos e técnicas de pesquisa em turismo. São Paulo: Futura.

DIAS, Reinaldo. 2003. Turismo sustentável e meio ambiente. São Paulo: Atlas.

FARIA, Ivani Ferreira de. 2001. Turismo sustentabilidade e novas territorialidades. Manaus, AM: Editora da Universidade do Amazonas.

FENNEL, David. A.2002. Ecoturismo: uma introdução. São Paulo: Contexto.

FUMDHAM. 2006. Parque Nacional Serra da Capivara. Disponível em: http://www.fumdham.org.br. Acesso em: jun 2006.

IBGE. 2006. Informações municipais. Disponível em: http://www.ibge.gov.br. Acesso em: ago 2006. . 2000. Censo demográfico. Rio de Janeiro.

IGNARRA, Luiz Renato. 2001. Fundamentos do turismo. São Paulo: Pioneira Thomson Learning.

KINKER, Sônia. 2002. Ecoturismo e conservação da natureza em parques nacionais. Campinas, SP: Papirus.

MARTINS, Espedito. Cezário. 2002. O turismo como alternativa de desenvolvimento sustentável: o caso de Jericoacoara no Ceará. Disponível em: < http://www.usp.br/teses.htm>. Acesso em: out 2002.

MINISTÉRIO DO TURISMO. 2006. Projeto de desenvolvimento sustentável do turismo da região do Parque Nacional Serra da Capivara. Brasília.

OLIVEIRA, Antônio Pereira de. 2000. Turismo e desenvolvimento: planejamento e organização. São Paulo: Atlas.

ORTIZ, Ramon Arigoni. 2003. Valoração econômica ambiental. In.: MAY, Peter. H., LUSTOSA, Maria Cecília, VINHA, Valéria da. (Orgs.). Economia do meio ambiente: teoria e prática. Rio de Janeiro: Elsevier.

PNUD. 2003. Atlas do desenvolvimento humano no Brasil 2000. Disponível em: $<$ http://www.pnud.org.br>. Acesso em: set 2003.

. 2002a. Plano referencial de desenvolvimento do município de São Raimundo Nonato. Disponível em: <http://www.pnud.org.br>. Acesso em: set 2003.

2002b. Plano referencial de desenvolvimento do município de Coronel José Dias. Disponível em: <http://www.pnud.org.br>. Acesso em: set 2003.

RODRIGUES, Adyr Balastreri. (org.). 2003. Ecoturismo no Brasil: possibilidades e limites. São Paulo: Contexto.

REJOWSKI, Mirian (org.). 2002. Turismo no percurso do tempo. São Paulo: Aleph.

SNUC. 2000. Sistema Nacional de Unidades de Conservação da Natureza. Lei Federal n 9.985, de 18 de julho de 2000.

SWARBROOKE, John. 2000. Turismo sustentável: turismo cultural, ecoturismo e ética. v.5. São Paulo: Aleph.

TRIGO, Luiz Gonzaga Godoi. 1993. Turismo e qualidade: tendências contemporâneas. Campinas, SP: Papirus.

Recebido em: 30/08/2007 (1 ${ }^{\text {a }}$ versão) $\quad 17 / 01 / 2008$ ( $2^{\text {a }}$ versão) $\quad 30 / 05 / 2008$ ( $3^{\text {a }}$ versão) 07/11/2008 ( $4^{\text {a }}$ versão)

Aprovado em: 14/02/2009 